\title{
A novel effective chemical hemin for the treatment of acute carbon monoxide poisoning in mice
}

\author{
HUI-MIN LI ${ }^{1-3}$, YING-LU SHI ${ }^{3}$, DI WEN ${ }^{3}$, HUAN-MIN LUO ${ }^{1}$, XI LIN $^{1,4}$ and FEI XIAO ${ }^{1,4}$ \\ ${ }^{1}$ Department of Pharmacology, School of Medicine; ${ }^{2}$ The Second Clinical Medical College; \\ ${ }^{3}$ International School of Clinical Medicine; ${ }^{4}$ Guangzhou Key Laboratory of Environmental \\ Exposure and Health, Jinan University, Guangzhou, Guangdong 510632, P.R. China
}

Received May 20, 2016; Accepted March 24, 2017

DOI: $10.3892 / \mathrm{etm} .2017 .5157$

\begin{abstract}
There is no effective drug for the therapy of acute carbon monoxide (CO) poisoning. The purpose of the present study was to investigate the potential preventive and therapeutic effects of hemin on an animal model of acute $\mathrm{CO}$ poisoning and to provide a potential therapeutic candidate drug. A total of 80 Kunming mice were randomly divided into four groups, namely the air control, acute $\mathrm{CO}$ poisoning, hemin-treatment $+\mathrm{CO}$ and hemin-pretreatment $+\mathrm{CO}$ groups $(n=20$ each). Furthermore, the mortality rate of mice, blood carboxyhaemoglobin $(\mathrm{HbCO})$ concentration and serum malondialdehyde (MDA) concentration were measured, and pathological changes of the hippocampal area were determined using histochemical staining. The mice with acute $\mathrm{CO}$ poisoning had a $50 \%$ mortality rate at $1 \mathrm{~h}$, with an increase in blood $\mathrm{HbCO}$, serum MDA levels and pathological impairments of the hippocampus. Furthermore, the mortality rate, blood $\mathrm{HbCO}$ and serum MDA levels of mice with pretreatment and treatment of hemin were decreased. Additionally, the pathological changes of the hippocampal area were improved in the hemin-treatment and hemin-pretreatment groups compared with the mice treated with $\mathrm{CO}$. These results suggest that hemin is a novel effective chemical for the prevention and treatment of acute $\mathrm{CO}$ poisoning in mice. Therefore, the present study provides a novel method and experimental basis for the application of hemin in treating patients with acute $\mathrm{CO}$ poisoning.
\end{abstract}

Correspondence to: Dr Xi Lin or Dr Fei Xiao, Department of Pharmacology, School of Medicine, Jinan University, 601 West Huangpu Avenue, Guangzhou, Guangdong 510632, P.R. China

E-mail: tlinxi@jnu.edu.cn

E-mail: xiaofei@jnu.edu.cn

Key words: acute carbon monoxide poisoning, hemin, animal model, carboxyhaemoglobin, oxidative stress

\section{Introduction}

Carbon monoxide (CO) is one of the most common types of asphyxiant poisoning gas in industrial manufacture and daily life, and both the incidence and mortality rates $(2.24 / 100,000$ in Europe in 2005) (1) of acute CO poisoning are the highest among cases of acute gas poisoning (2). Clinically, hyperbaric oxygen chamber therapy is the suggested treatment for acute $\mathrm{CO}$ poisoning (3), as high pressure may accelerate the dissociation of carboxyhaemoglobin ( $\mathrm{HbCO})$ to increase the discharge of CO (4). However, the therapeutic mechanism and effect of hyperbaric oxygen chamber therapy for treating post-CO poisoning encephalopathy remain unproven $(5,6)$, and the therapy is not always readily available. In addition, dexamethasone and hypertonic glucose dehydration therapy are often used to prevent or treat delayed encephalopathy (7); however these treatments act only as symptomatic therapies or are used to prevent $\mathrm{CO}$ poisoning complications. A recent hypothesis indicated that an antioxidant such as caffeic acid phenethyl ester and anti-nitric oxide therapy may be valuable for neuroprotection against $\mathrm{CO}$ poisoning (8). Thus far, the majority of research studies (9-11) have focused on the treatment for delayed encephalopathy caused by $\mathrm{CO}$ poisoning, whereas few (12) have reported the emergency treatment for $\mathrm{CO}$ poisoning.

Hemin is an artificially synthesized chloride of heme, with similar chemical characteristics (13). Furthermore, hemin may increase the oxygen carrying capacity and may compete with $\mathrm{HbCO}$ to bind $\mathrm{CO}$ to increase the body tolerance to hypoxia. In addition, hemin is an activator of neuroglobin (14). Neuroglobin participates in oxygen transport and storage in neurons, helps increase the intracellular partial pressure of oxygen in neurons, and is important in protecting neurons from hypoxic injury. A previous animal study indicated that hemin is able to induce heme oxygenase-1 activity to show neuroprotection (15). Although there is no current evidence in clinical trials, it was hypothesized that hemin may be able to prevent and treat acute $\mathrm{CO}$ poisoning. Due to the lack of effective drug therapies in clinically treating acute $\mathrm{CO}$ poisoning and the high mortality rate among $\mathrm{CO}$-poisoned patients, the aim of the present study was to identify novel therapeutic options to reduce the mortality rate of patients with $\mathrm{CO}$ poisoning. To test this hypothesis, the potential protective effect of hemin 
on acute $\mathrm{CO}$ poisoning was examined in mice. In the present study, an animal model was generated by single intraperitoneal injection of CO to Kunming mice (16). Using preventive and therapeutic injection of hemin, its preventive function and therapeutic effect was studied on acute $\mathrm{CO}$ poisoning in the mice model; in particular, the present study attempted to establish whether hemin administration was able to reduce the mortality rate.

\section{Materials and methods}

Animals. A total of 280 Kunming mice (male:female ratio, 1:1), aged 5 weeks, weighing 18-22 g, were obtained from Guangdong Medical Laboratory Animal Centre (Foshan, China). All mice were raised in the Jinan University Medical Pharmacology Laboratory (Guangzhou, China) with controlled temperature $\left(25^{\circ} \mathrm{C}\right)$, humidity (50-60\%) and $12 \mathrm{~h}$ light:dark cycle. Animals were acclimatised with ad libitum access to standard laboratory food and tap water for one week and fasted for $24 \mathrm{~h}$ prior to all experiments. The experimental protocol of the present study was approved by the Jinan Medical University Animal Care Committee.

Chemicals and reagents. CO (purity $>99.90 \%$ ) was purchased from Guangzhou Wanqiqiti, Ltd. (Guangzhou, China), hemin was purchased from Sigma-Aldrich (Merck KGaA, Darmstadt, Germany) and a commercial Malondialdehyde (MDA) Assay kit (TBA method) was purchased from the Nanjing Jiancheng Bioengineering Institute (Nanjing, China). Formaldehyde (3.5\%) and sodium phosphate were purchased from Guangzhou Chemical Reagent Factory (Guangzhou, China). All other chemicals were of the highest quality commercially available.

Determination of $\mathrm{CO}$ model and optimal dose of hemin. A total of 60 Kunming mice, weighing 18-22 g, were divided into six groups $(\mathrm{n}=10$ each) used for acute $\mathrm{CO}$ exposure in order to determine the median lethal dose (LD50). A dose of $60 \mathrm{ml} / \mathrm{kg}$ was used as the initial exposure dose via intraperitoneal injection. Results from the initial exposure dose $(60 \mathrm{ml} / \mathrm{kg})$ were used to select the subsequent doses $(90,135,202.5,303.8$ and $455.7 \mathrm{ml} / \mathrm{kg}$ ), and by these up-and-down procedures (17), the mortality and 1-h mortality rate were recorded. The modified Spearman-Karber method (18) was used to calculate LD50 and to identify the lower limit of the calculated LD50 as the administration dose $(150 \mathrm{ml} / \mathrm{kg})$.

The optimal dose of hemin used in the present study was based on the results of preliminary experiments. In the preliminary experiment, 100 Kunming mice were divided into five groups $(\mathrm{n}=20 \mathrm{each})$, including the air control, CO-poisoning, low $(10 \mathrm{mg} / \mathrm{kg})$, moderate $(20 \mathrm{mg} / \mathrm{kg})$ and high dose $(40 \mathrm{mg} / \mathrm{kg})$ of hemin groups. CO was administered at the LD50 $(150 \mathrm{ml} / \mathrm{kg})$ via intraperitoneal injection. Mice exposed to $\mathrm{CO}$ were administered intraperitoneally with a dose of hemin $(10,20$ or $40 \mathrm{mg} / \mathrm{kg})$ when they started to show symptoms of $\mathrm{CO}$ toxicity, such as anxiety and hyperactivity. The air control group was administered intraperitoneally with a dose of air $(150 \mathrm{ml} / \mathrm{kg})$ and an equivalent volume of phosphate-buffered saline [PBS; $0.1 \mathrm{M}$ sodium phosphate ( $\mathrm{pH} 7.2), 0.9 \%$ saline]. The 1-h mortality rate of mice in the different groups was then recorded.
Animal grouping and drug treatment. A total of 80 Kunming mice (18-22 g) were randomly divided into four groups $(\mathrm{n}=20$ each) as follows: i) Air control, mice were injected intraperitoneally with air using the same dosage as LD50 $(150 \mathrm{ml} / \mathrm{kg})$ and PBS solvent (40 mg/kg); ii) CO-poisoning group, $\mathrm{CO}$ poisoning was induced in mice using the dosage of LD50 by a single intraperitoneal injection (15) and treated with the same dose of PBS solvent; iii) hemin-treatment + CO-poisoning group, mice were injected intraperitoneally with hemin (40 mg/kg) 2 min after CO exposure, when mice began to exhibit symptoms of toxicity; and iv) hemin-pretreatment + CO-poisoning group, hemin $(40 \mathrm{mg} / \mathrm{kg})$ was administered to mice $15 \mathrm{~min}$ prior to $\mathrm{CO}$ exposure.

Mortality and survival curve. Physical and behavioral changes in the mice were recorded. These included the time when the skin or mucosa of mice turned to cherry red and the times when the mice exhibited hyperactivity, opisthotonus or fatigue. Mortality at $1 \mathrm{~h}$ was calculated as the number of dead mice at $1 \mathrm{~h}$ /number of mice in each group. Furthermore, the time of death was recorded and the survival curve plotted.

Determination of blood $\mathrm{HbCO}$ concentration. $\mathrm{HbCO}$ was determined by double-wavelength spectrophotometry (19), which was measured as the resistance of $\mathrm{HbCO}$ to reduction by sodium dithionite $\left(\mathrm{Na}_{2} \mathrm{~S}_{2} \mathrm{O}_{4}\right)$ compared with reduced oxyhaemoglobin. $\mathrm{HbCO}$ has peak absorbance at a wavelength of $535 \mathrm{~nm}$, whereas that of oxyhaemoglobin is at $578 \mathrm{~nm}$. Therefore, this quotient was used to determine the $\mathrm{HbCO}$ concentration according to the experimental equation:

$$
\operatorname{HbCO}(\%)=\left(2.44 \times \frac{\mathrm{A} 535}{\mathrm{~A} 578}-2.68\right) \times 100 \%
$$

A535 is absorbance in $\lambda$ at $535 \mathrm{~nm}$; A578 is absorbance in $\lambda$ at $578 \mathrm{~nm}$. A total of 10 mice were randomly selected in each group and from each mouse $0.1 \mathrm{ml}$ blood was harvested from the tail 30 min after $\mathrm{CO}$ exposure. Blood was collected in a dry Eppendorf tube that was rinsed with heparin in advance. Subsequently, $0.1 \mathrm{ml}$ blood was mixed thoroughly by inversion with $20 \mathrm{ml}$ of $0.4 \mathrm{~mol} / \mathrm{l}$ ammonia solution and $20 \mathrm{mg} \mathrm{Na} \mathrm{S}_{2} \mathrm{~S}_{2}$ was then added. This mixed reducing reagent was measured by a spectrophotometer (EnSpire 2300; PerkinElmer, Inc., Waltham, MA, USA) at 535 and $578 \mathrm{~nm}$ wavelengths, respectively, within $10 \mathrm{~min}$ due to the instability of the reducing reagent. $\mathrm{HbCO}$ concentration could be calculated by the experimental equation.

Determination of serum MDA concentration. MDA, which is a parameter of oxidative stress, was measured by the thiobarbituric acid (TBA) method (20). MDA reacts with TBA to form red-coloured MDA-reactive products with a peak absorbance at a wavelength of $535 \mathrm{~nm}$. Therefore, spectrophotometry was used to determine the serum MDA concentration.

In total, 10 mice in each group were randomly selected, and from each mouse, $0.1 \mathrm{ml}$ blood was collected from the caudal veins at 5 and 30 min after $\mathrm{CO}$ exposure. Each blood sample was thoroughly mixed with $0.5 \mathrm{ml}$ normal saline $(0.9 \%)$ and $0.5 \mathrm{ml} \mathrm{TBA}(0.5 \%)$, and this mixture was heated at $95^{\circ} \mathrm{C}$ for $40 \mathrm{~min}$. Following cooling to room temperature, the sample 
Table I. Mortality rates of mice after intraperitoneal injection at different doses of carbon monoxide.

\begin{tabular}{lccc}
\hline $\begin{array}{l}\text { Dose } \\
(\mathrm{ml} / \mathrm{kg})\end{array}$ & Mice (n) & Mortality (n) & $\begin{array}{c}\text { 1-h mortality } \\
\text { rate }(\%)\end{array}$ \\
\hline 60.0 & 10 & 0 & 0 \\
90.0 & 10 & 1 & 10 \\
135.0 & 10 & 4 & 40 \\
202.5 & 10 & 6 & 60 \\
303.8 & 10 & 9 & 90 \\
455.7 & 10 & 10 & 100 \\
\hline
\end{tabular}

LD50 value calculated using the modified Spearman-Karber method was $166 \mathrm{ml} / \mathrm{kg}$ (95\% confidence intervals: 150 to $169 \mathrm{ml} / \mathrm{kg}$ ). In the following experiment, the lower limit of LD50 was set as the poisoning dose for animal models, which was $150 \mathrm{ml} / \mathrm{kg}$, intraperitoneally. LD50, median lethal dose.

was centrifuged at $2,683 \mathrm{xg}$ for $10 \mathrm{~min}$. A $0.1-\mathrm{ml}$ aliquot of protein-free supernatant was separated from the mixture, and the intensity of the end fraction product was examined at a wavelength of $532 \mathrm{~nm}$ (21). Therefore, the serum MDA concentration was calculated according to the specification provided in the MDA kit.

Hematoxylin and eosin $(H \& E)$ and Nissl staining. Mice were sacrificed $1 \mathrm{~h}$ after $\mathrm{CO}$ exposure, and hippocampal tissues were removed immediately for histological observation (22). The mice were deeply anaesthetised with sodium pentobarbital $(50 \mathrm{mg} / \mathrm{kg}$, intraperitoneally) and perfused through the heart with $200 \mathrm{ml}$ of a solution containing 3.5\% formaldehyde and phosphate-buffered saline [0.1 M sodium phosphate ( $\mathrm{pH} 7.2), 0.9 \%$ saline]. The brain was removed and preserved in the same fixative solution for 7 days at room temperature $\left(222^{\circ} \mathrm{C}\right)$, then embedded in hard paraffin at $60^{\circ} \mathrm{C}$ for $5 \mathrm{~h}$. Then, $5-\mu \mathrm{m}$-thick coronal sections were prepared. The hippocampal CAl area was selected from the serial sections, which was $1.5 \mathrm{~mm}$ in length $(6 \mathrm{~mm}$ posterior to the bulbous olfactorius, according to the atlas) (23). The selected sections were then treated with $\mathrm{H} \& \mathrm{E}$ and Nissl's staining. Furthermore, the pathological changes in the hippocampal $\mathrm{CAl}$ area of the specimens were observed under low-power (magnification, x40) and high-power field (magnification, $\mathrm{x} 400$ ) light microscopy, and images were captured using an image scanner (Bio-Rad Laboratories, Inc., Hercules, CA, USA).

Statistical analysis. The data belonged to nonparametric data, which are expressed as median and interquartile ranges. A significant difference between the two groups was analyzed by the Mann-Whitney U test, whereas categorical variables were analyzed by the $\chi^{2}$ test. Furthermore, biochemical data are expressed as the mean \pm standard error of the mean, which were calculated by one-way analysis of variance followed by the Bonferroni test for multiple-group comparisons or evaluated by the Student's t-test for two-group comparisons. Finally, the analyses were performed with SSPS software (version
Table II. Mortality rates of CO-poisoned mice after treatment with different doses of hemin.

\begin{tabular}{lccc}
\hline Group & Mice (n) & Mortality (n) & $\begin{array}{c}\text { 1-h mortality } \\
\text { rate }(\%)\end{array}$ \\
\hline Control & 20 & 0 & 0.0 \\
$\begin{array}{l}\text { CO poisoning } \\
\text { Low dose of hemin }\end{array}$ & 20 & 10 & $50.0^{\mathrm{a}}$ \\
$\left(\begin{array}{l}10 \mathrm{mg} / \mathrm{kg}) \\
\text { Moderate dose of } \\
\text { hemin }(20 \mathrm{mg} / \mathrm{kg})\end{array}\right.$ & 20 & 7 & $40.0^{\mathrm{b}}$ \\
$\begin{array}{l}\text { High dose of hemin } \\
(40 \mathrm{mg} / \mathrm{kg})\end{array}$ & 20 & 4 & $35.0^{\mathrm{b}}$ \\
\hline
\end{tabular}

High dose $(40 \mathrm{mg} / \mathrm{kg})$ of intraperitoneal hemin was selected as the optimal therapeutic dose. ${ }^{\mathrm{a}} \mathrm{P}<0.01$ vs. control group, ${ }^{\mathrm{b}} \mathrm{P}<0.05,{ }^{\mathrm{c}} \mathrm{P}<0.01$ vs. $\mathrm{CO}$ poisoning group. $\mathrm{CO}$, carbon monoxide.

13.0; SPSS, Inc., Chicago, IL, USA). $\mathrm{P}<0.05$ was considered to indicate a statistically significant difference.

\section{Results}

Establishment of an animal model of acute CO poisoning. Initially, the LD50 of acute $\mathrm{CO}$ poisoning was measured using the modified Spearman-Karber method. Six different CO dosages were evaluated according to geometric progression, with a group interval of $1.5(60.0,90.0,135.0,202.5,303.8$ and $455.7 \mathrm{ml} / \mathrm{kg}$ ), and administered via a single intraperitoneal injection. The 1-h mortality rate of mice was presented in Table I and the calculated LD50 was $150 \mathrm{ml} / \mathrm{kg}$.

Determination of the optimal dose of hemin. It was revealed that the mortality rate following administration of a high dose of hemin $(40 \mathrm{mg} / \mathrm{kg})$ was markedly lower than that of the low $(10 \mathrm{mg} / \mathrm{kg})$ and moderate $(20 \mathrm{mg} / \mathrm{kg})$ dosage groups (Table II). Therefore, in the following experiments, $40 \mathrm{mg} / \mathrm{kg}$ was used as the optimum therapeutic dose of hemin.

Hemin reduced the mortality rate of CO-poisoned mice. The mortality rate of mice at $1 \mathrm{~h}$ was $50.0 \%$ in the acute CO-poisoning group; $20.0 \%$ in the hemin-treated and $5.0 \%$ in the hemin-pretreated groups. Furthermore, the $\chi^{2}$ test indicated that there was a significant difference in the mortality rate of mice at $1 \mathrm{~h}$ between the CO-intoxication and hemin-treated groups $(\mathrm{P}<0.05)$, and between the $\mathrm{CO}$-intoxication and hemin-pretreated groups $(\mathrm{P}<0.01)$ (Table III).

Hemin alleviated the symptoms of acute CO poisoning. In the control group, no abnormal reaction manifestation was observed. In the CO-poisoning group, following intraperitoneal injection of $\mathrm{CO}$, symptoms of poisoning were evident. At 2 min, the skin and mucosa of mice began to turn cherry red. At 5-7 min, mice became anxious and hyperactive and after 15 min mice exhibited fatigue and weakness of the limbs, and the skin and mucosa turned cherry red as well. In addition, they showed generalized convulsion, and 4 mice exhibited 
Table III. Mortality rate of acute CO-poisoned mice.

\begin{tabular}{lccc}
\hline Group & Mice (n) & Mortality (n) & $\begin{array}{c}\text { 1-h mortality } \\
\text { rate (\%) }\end{array}$ \\
\hline Control & 20 & 0 & 0.0 \\
CO poisoning & 20 & 10 & $50.0^{\mathrm{a}}$ \\
Hemin-treatment & 20 & 4 & $20.0^{\mathrm{b}}$ \\
Hemin-pretreatment & 20 & 1 & $5.0^{\mathrm{c}}$ \\
\hline
\end{tabular}

${ }^{\mathrm{a}} \mathrm{P}<0.01$ vs. control group, ${ }^{\mathrm{b}} \mathrm{P}<0.05,{ }^{\mathrm{C}} \mathrm{P}<0.01$ vs. $\mathrm{CO}$ poisoning group. $\mathrm{CO}$, carbon monoxide.

opisthotonus. After $30 \mathrm{~min}, \mathrm{CO}$-poisoned mice became less active and did not react to tactile stimuli. In the hemin-treated $\mathrm{CO}$-poisoned group, at $2 \mathrm{~min}$ after $\mathrm{CO}$ injection, mice became anxious and the skin and mucosa started to turn cherry red. However, following injection of hemin, the time when the symptoms of poisoning appeared was postponed. In total, $10 \mathrm{~min}$ after intoxication, mice became anxious again and after $45 \mathrm{~min}$ the mice became quiet and stayed still together, while 2 mice appeared to be opisthotonus. In the hemin-pretreated $\mathrm{CO}$-poisoned group, at $3 \mathrm{~min}$ after $\mathrm{CO}$ injection, the mice started to become hyperactive and the skin and mucosa started to turn cherry red. At $14 \mathrm{~min}$, mice exhibited anxiety, while none of the mice exhibited opisthotonus. At $50 \mathrm{~min}$, the mice appeared quiet again.

Hemin prolonged the survival time of $\mathrm{CO}$-poisoned mice. The mean mortality time in the CO-intoxication group was $29.4 \mathrm{~min}$ (minimum, $16 \mathrm{~min}$; maximum, $42 \mathrm{~min}$ ), whereas it was increased to a mean of $43.3 \mathrm{~min}$ in the hemin-treatment group (minimum, $30 \mathrm{~min}$; maximum, $50 \mathrm{~min}$ ) and only 1 mouse died at $51.0 \mathrm{~min}$ in the hemin-pretreatment group. The mean mortality time of the control group was $>1 \mathrm{~h}$; therefore, the survival rates of control groups was $100 \%$ (Fig. 1). Furthermore, there was a statistically significant difference between the death time of both the hemin-treatment group and hemin-pretreatment group and that of the $\mathrm{CO}$-poisoning group $(\mathrm{P}<0.05$ and $\mathrm{P}<0.01$, respectively).

Hemin decreased the level of $\mathrm{HbCO}$ of $\mathrm{CO}$-poisoned mice. The $\mathrm{HbCO}$ level of mice $30 \mathrm{~min}$ following administration of $\mathrm{CO}$ is presented in Fig. 2. The HbCO level of the $\mathrm{CO}$-poisoning group was significantly higher than that of the hemin-treatment group $(\mathrm{P}<0.01)$. Additionally, there was a statistically significant difference between the $\mathrm{HbCO}$ level of the hemin-pretreatment and that of the $\mathrm{CO}$-poisoned groups $(\mathrm{P}<0.01)$.

Hemin reduced the serum MDA concentration in CO-poisoned mice. The serum MDA concentration in each group subjected to $\mathrm{CO}$ poisoning increased following exposure, and there was no statistically significant difference between the MDA concentration of each group 5 min after intoxication. At $30 \mathrm{~min}$ following $\mathrm{CO}$ intoxication, a statistically significant difference was observed between the serum MDA concentration of the CO-poisoning group and both the hemin treatment and hemin pretreatment groups (both $\mathrm{P}<0.01$ ). Furthermore, there was no

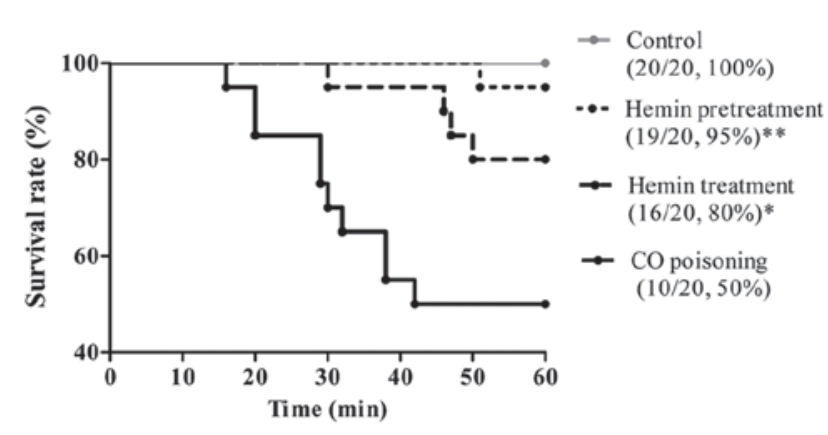

Figure 1. Effect of hemin on the survival rate of acute $\mathrm{CO}$-poisoned mice. ${ }^{*} \mathrm{P}<0.05$ and ${ }^{* *} \mathrm{P}<0.01$ vs. the $\mathrm{CO}$ poisoning group. $\mathrm{CO}$, carbon monoxide.

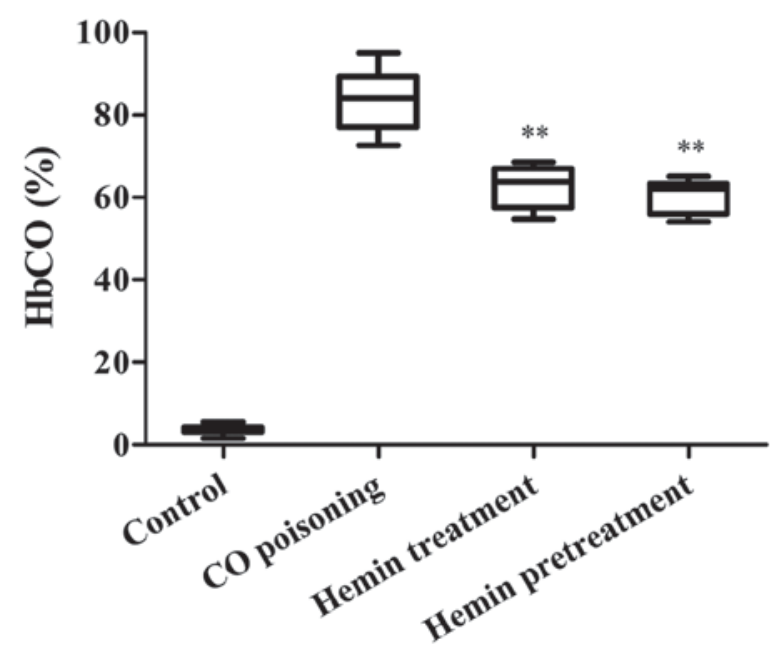

Figure 2. HbCO level of mice $30 \mathrm{~min}$ after acute $\mathrm{CO}$ poisoning. ${ }^{* * *} \mathrm{P}<0.01$ vs. the $\mathrm{CO}$ poisoning group. $\mathrm{HbCO}$, carboxyhaemoglobin; $\mathrm{CO}$, carbon monoxide.

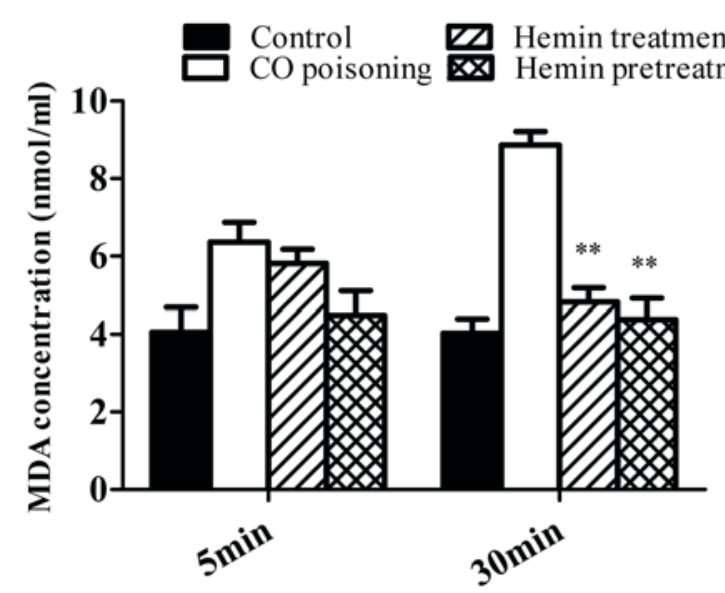

Figure 3. Changes in serum MDA concentration of the caudal vein after intraperitoneal $\mathrm{CO}$ intoxication $(\mathrm{nmol} / \mathrm{ml}) .{ }^{* *} \mathrm{P}<0.01$ vs. the $\mathrm{CO}$ poisoning group. Data shown are the mean \pm standard error of three independent experiments. $\mathrm{CO}$, carbon monoxide; MDA, malondialdehyde.

statistically significant difference between the MDA concentration of the control group at 5 and 30 min (Fig. 3).

Pathological changes in the hippocampus of mice. HE staining (Fig. 4) indicated that there was swelling of cells at 

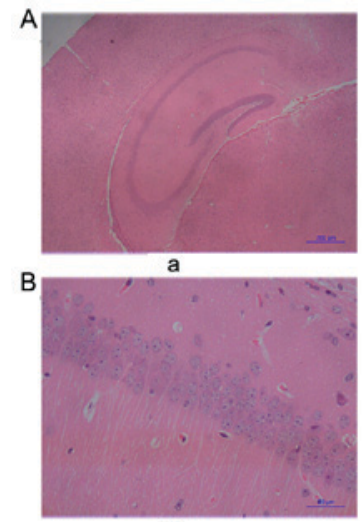
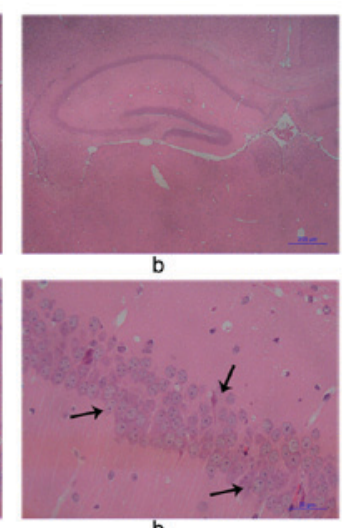

b
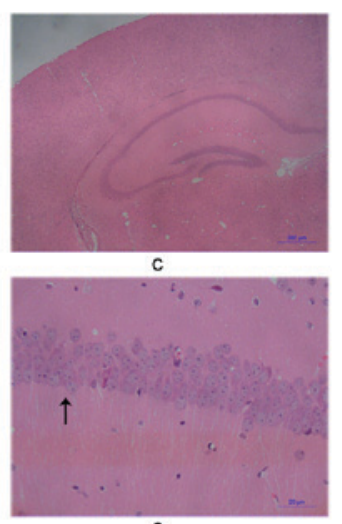
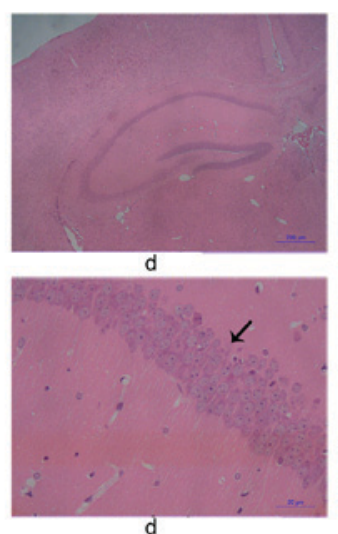

Figure 4. Representative morphological characteristics (hematoxylin and eosin staining) in the hippocampus of mice from (Aa) the control, (Ab) CO poisoning, (Ac) hemin treatment and (Ad) hemin pretreatment (magnification, $\mathrm{x} 40$ ); and those from (Ba) the control, $(\mathrm{Bb}) \mathrm{CO}$ poisoning, (Bc) hemin treatment and (Bd) hemin pretreatment, (magnification, $\mathrm{x} 400$ ). The degeneration or disarrangement of cells is indicated by black arrows. CO, carbon monoxide.

the CA1 region of the hippocampus and dentate gyrus, and that the number of pyramidal cells decreased. Some neurons underwent necrosis and exhibited pyramidal cells that were triangular or polygonal in shape, reduced in size and undergoing karyopyknosis with unclear nucleoli (Fig. 4Ab). In the control group, there were no marked changes to the neurons in any region of the hippocampus in either side of the brain. Furthermore, there was no swelling or necrosis, which indicated that the cells were healthy (Fig. 4Aa). Compared with the CO-poisoning group, the swelling of neurons in the hippocampus of mice in the hemin-treated and hemin-pretreated groups was less evident, the number of cells undergoing necrosis decreased and the cell arrangements for both groups were more orderly (Fig. 4Ac and d). The morphology of cells exhibited unclear cell boundaries with several necrotic cells (Fig. 4Bb). In the control group, there were no evident pathological changes in the nerve cells, and they exhibited aligned nuclei (Fig. 4Ba). Compared with the CO-poisoning group, the hemin-treated and hemin-pretreated groups exhibited clearer boundaries with fewer necrotic cells (Fig. 4Bc and d).

Nissl staining (Fig. 5) indicated that, in the CO-poisoning group, the neurons of the hippocampus CA1 region were swollen and the number of Nissl bodies decreased. Some neurons underwent necrosis with unclear nucleoli and irregular boundaries (Fig. 5Ab). In the control group, there were no marked changes to the neurons in any region of the hippocampus in either side of the brain (Fig. 5Aa). Compared with the CO-poisoning group, the swelling of neurons in the hippocampus of mice in the hemin-treated and hemin-pretreated groups was less evident; there were fewer necrotic cells and the cell arrangements were more orderly (Fig. 5Ac and d). In addition, the morphology of cells was irregular with unclear boundaries accompanied by nuclei undergoing karyopyknosis (Fig. 5Bb). In the control group, there were no evident pathological changes in the nerve cells, which indicated that no swelling or necrosis had occurred (Fig. 5Ba). Compared with the CO-poisoning group, the cell arrangements in the hemin-treated and hemin-pretreated groups were more regular, the number of Nissl bodies markedly decreased and fewer necrotic cells were observed (Fig. 5Bc and d).

\section{Discussion}

In clinical settings, the initial management of patients with $\mathrm{CO}$ poisoning consists of removing the patient from exposure to the toxic atmosphere and supplying pure oxygen to accelerate the elimination of $\mathrm{CO}$ and improve tissue oxygenation (24). The exposure to acute $\mathrm{CO}$ poisoning is primarily by inhalation. Therefore, $\mathrm{CO}$ poisoning animal models were previously established by inhalation, which may be classified as either dynamic or static exposure (25). Dynamic exposure, which is similar to routine human inhalation, may negate the interference of other non-toxic factors such as asphyxia. However, due to the high cost of requirements and higher demand of hermeticity, the extensive use of this approach is not convenient. Conversely, static exposure is simple, but it is difficult to prevent hypoxia induced by $\mathrm{CO}_{2}$ and other interferential factors. Therefore, the results may not be accurate.

Previous research has demonstrated that the establishment of an acute $\mathrm{CO}$ poisoning model by intraperitoneal injection is a convenient and effective animal model (15). Compared with inhalation exposure, intraperitoneal injection of $\mathrm{CO}$ results in a more precise $\mathrm{CO}$ exposure dose which is more suitable for scientific research. It has been demonstrated that if the level of $\mathrm{HbCO}$ in the blood is $>10 \%$, toxic reactions can be observed; at levels of $\geq 30 \%$, moderate poisoning can be observed and at $50 \%$ severe poisoning (26). Furthermore, a single injection may result in $\mathrm{HbCO}$ levels rapidly reaching $>60 \%$, and maintaining stability at $50 \%$ within $6 \mathrm{~h}$. Additionally, a single intraperitoneal injection of $\mathrm{CO}$ exhibits the same poisoning mechanism and symptoms as those in the clinical settings (27), even though its exposure route is different from clinical acute $\mathrm{CO}$ poisoning. In the present study, a modified Spearman-Karber method was used to determine a single intraperitoneal injection lethal dose that was the lower limit of the median lethal dose (LD50) (28). In the present study, following a single intraperitoneal injection of $\mathrm{CO}$, significant $\mathrm{CO}$ poisoning manifestations were observed in mice. Furthermore, the binding ability of haemoglobin to oxygen was significantly reduced resulting in tissue hypoxia and lipid peroxidation, and blood MDA levels increased rapidly and pathological changes in the hippocampal cells were observed. In conclusion, the mouse model of the present 


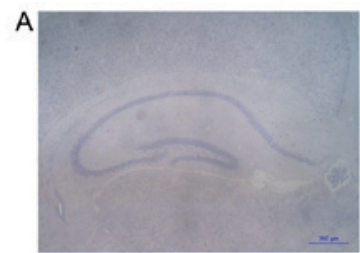

a

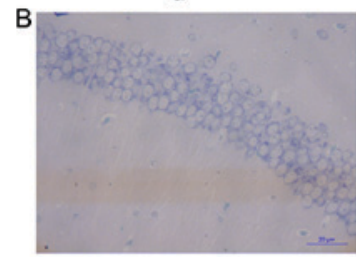

a
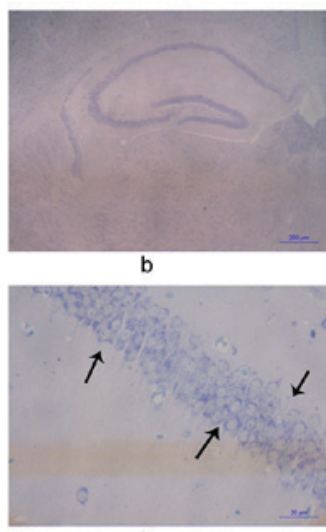

b
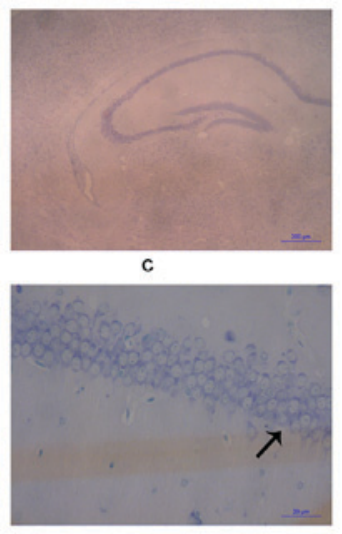

c

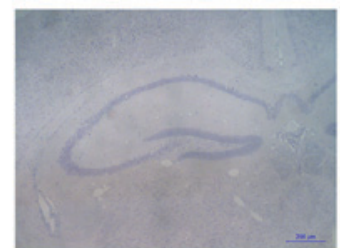

d

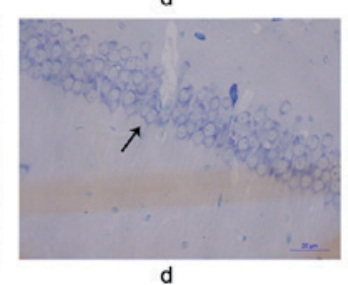

Figure 5. Representative images of Nissl staining of the hippocampus in the mice. The effects of hemin on neurons in the hippocampus of mice from (Aa) the control, (Ab) CO poisoning, (Ac) hemin treatment and (Ad) hemin pretreatment, (magnification, $\mathrm{x} 40$ ); and those from (Ba) control, (Bb) $\mathrm{CO}$ poisoning, (Bc) hemin treatment and $(\mathrm{Bd})$ hemin pretreatment, (magnification, $\mathrm{x} 400)$. The degeneration or disarrangement of cells is indicated by the arrows. CO, carbon monoxide.

study was established via a single intraperitoneal injection of $\mathrm{CO}$ that successfully simulated the pathogenic process of $\mathrm{CO}$ poisoning as observed in clinical settings.

Hemin, as a synthetic heme chloride with a high absorption rate, is recognized as a good source of iron to prevent iron deficiency in anemia (14). Hemin that has the property to combine with oxygen is able to improve the oxygen carrying capacity of blood (13). Furthermore, hemin is also an activator of neuroglobin (29), the oxygen carrier that participates in transportation and storage of oxygen in neurons and subsequently increases the oxygen concentration within neurons. Therefore, hemin may be a potential therapeutic agent to relieve hypoxia following $\mathrm{CO}$ exposure.

The present study demonstrated that both pretreatment and treatment with hemin to mice with $\mathrm{CO}$ poisoning was able to significantly reduce their mortality rate. Furthermore, it is able to reduce toxic injury in mice, which was demonstrated by the prolonged onset of symptoms in mice and a significant decrease in the blood $\mathrm{HbCO}$ level. In $\mathrm{CO}$ poisoning, hypoxia has a proportional association with the $\mathrm{HbCO}$ level (30), and therefore, the present results indicated that the degree of poisoning in the pretreatment and treatment groups has been reduced compared with that in the CO-poisoning group. According to these results, the protective mechanism of hemin against $\mathrm{CO}$ poisoning may be due to a reduction in the blood $\mathrm{HbCO}$ level, which prevents oxygen transfer. Furthermore, it may be because hemin replaces $\mathrm{HbCO}$ into oxyhaemoglobin to expel $\mathrm{CO}$ and thus, oxygen may be transported to the tissues by oxyhaemoglobin.

Hemin may also combine with free $\mathrm{CO}$ in the bloodstream and thus relieve tissue injury. In addition, a previous animal study provided evidence that hemin is able to induce heme oxygenase-1 (HO-1) activity leading to neuroprotection against acute $\mathrm{CO}$ poisoning (15). It is believed that HO-1 exhibits protective effects against exogenous $\mathrm{CO}$ toxicity (31) through degradation of heme into biliverdin and free iron that show potential biological effects $(32,33)$. By combining the above evidence with the results of the present study, it is suggested that it is another possible mechanism that involves the production of HO-1 induced by hemin (34) following acute $\mathrm{CO}$ exposure. However, further studies could be performed in this field to investigate the underlying molecular mechanisms.
The present study also demonstrated that MDA, the blood oxidative stress indicator, decreased significantly in both the hemin-pretreated and hemin-treated groups compared with in the CO-poisoning model group. It is believed that oxidative stress is essential in CO-induced neuronal damage (35). Furthermore, MDA is a common product of lipid peroxidation, which is able to reflect the systemic lipid peroxidation level and therefore indirectly reflects the degree of free radical attack and cell injury extent (36). Therefore, it is possible to measure oxygen radicals and lipid peroxidation level in the brain tissue via serum MDA content. The observations of the present study were consistent with the hypothesis that reactive oxygen species (ROS) may be associated with the acute toxic effects of $\mathrm{CO}$ on the central nervous system (8). Additionally, a sudden burst of ROS during ischemic-reperfusion injury in $\mathrm{CO}$ toxicity leads to cellular lipid peroxidation, and thus MDA may increase in acute $\mathrm{CO}$ poisoning. The decrease in MDA indicated that the protective effect of hemin for acute $\mathrm{CO}$ poisoning injury may be associated with the inhibition of lipid peroxidation, reducing ROS in the brain. Furthermore, in clinical settings, oxygen therapy following $\mathrm{CO}$-induced tissue hypoxia may be followed by ischemic-reperfusion injury in the CNS (37), leading to increased production of ROS such as nitric oxide (38). Therefore, it may be hypothesized that hemin may also be an alternative therapy to prevent secondary injury and thus protect the brain.

Histopathological examinations demonstrated that both hemin pretreatment and the hemin treatment in early stages could not only reduce hippocampus oedema and necrosis, but also the number of abnormal cells and neuronal damage. Since the hippocampal area is important in memory, learning and emotional activities, it is highly sensitive to hypoxia, asphyxia and ischemia because of its high metabolic rate (25). Furthermore, white and gray matter in the brain are sensitive to hypoxic damage due to the anatomic structure of poor vasculature (39). Therefore, the hippocampal area is able to show evident pathological changes in acute $\mathrm{CO}$ poisoning. Furthermore, the improvement in pathological changes in the hippocampal area revealed that $\mathrm{CO}$-induced impairment was significantly alleviated in mice pretreated or treated with hemin.

In conclusion, the present study found that hemin has protective effects of decreasing mortality and relieving hippocampus 
oedema in mice with acute $\mathrm{CO}$ poisoning. Furthermore, the potential protective mechanisms may include a decrease in the level of $\mathrm{HbCO}$, inhibition of lipid peroxidation and reduction of oxygen free radicals in brain cells. Meanwhile, the present study could provide reliable evidence of animal experiments for the treatment of acute $\mathrm{CO}$ poisoning. Finally, applications of hemin for acute $\mathrm{CO}$ poisoning may provide a reliable basis for future clinical treatment to gain rescue time and further decrease the mortality rate.

\section{Acknowledgements}

The present study was funded by the Natural Science Foundation of China (grant no. 81202519) and Guangdong Province (grant no. S2011040002140), and the Science and Technology Program of Guangzhou (grant no. 201607010216) and Challenge Cup of Jinan University (grant no. 15112024).

\section{References}

1. Braubach M, Algoet A, Beaton M, Lauriou S, Héroux ME and Krzyzanowski M: Mortality associated with exposure to carbon monoxide in WHO European Member States. Indoor Air 23: $115-125,2013$.

2. Prockop LD and Chichkova RI: Carbon monoxide intoxication: An updated review. J Neurol Sci 262: 122-130, 2007.

3. Weaver LK, Hopkins RO, Chan KJ, Churchill S, Elliott CG, Clemmer TP, Orme JF Jr, Thomas FO and Morris AH: Hyperbaric oxygen for acute carbon monoxide poisoning. N Engl J Med 347: 1057-1067, 2002

4. Pace N, Strajman E and Walker EL: Acceleration of carbon monoxide elimination in man by high pressure oxygen. Science 111: 652-654, 1950.

5. Hawkins M, Harrison J and Charters P: Severe carbon monoxide poisoning: Outcome after hyperbaric oxygen therapy. Br J Anaesth 84: 584-586, 2000.

6. Hampson NB and Zmaeff JL: Outcome of patients experiencing cardiac arrest with carbon monoxide poisoning treated with hyperbaric oxygen. Ann Emerg Med 38: 36-41, 2001.

7. Li Q, Song JJ, Zhang HY, Fu K, Lan HB and Deng Y: Dexamethasone therapy for preventing delayed encephalopathy after carbon monoxide poisoning. Biotech Histochem 90 561-567, 2015.

8. Akyol S, Yuksel S, Pehlivan S, Erdemli HK, Gulec MA, Adam B and Akyol O: Possible role of antioxidants and nitric oxide inhibitors against carbon monoxide poisoning: Having a clear conscience because of their potential benefits. Med Hypotheses 92: 3-6, 2016.

9. Wang H, Li Y, Wu Q, Xu C and Liu Q: Combination of butylphthalide with umbilical mesenchymal stem cells for the treatment of delayed encephalopathy after carbon monoxide poisoning. Medicine (Baltimore) 95: e5412, 2016.

10. Ochi S, Abe M,Li C, Mori Y, Ishimaru T, Yoshino Y, Yamazaki K, Mori T, Fukuhara R, Tanimukai S, et al: The nicotinic cholinergic system is affected in rats with delayed carbon monoxide encephalopathy. Neurosci Lett 569: 33-37, 2014.

11. Hu MC, Shiah IS, Yeh CB, Chen HK and Chen CK: Ziprasidone in the treatment of delayed carbon monoxide encephalopathy. Prog Neuropsychopharmacol Biol Psychiatry 30: 755-757, 2006.

12. O'Bryan EC, Veser FH, Veser B and Casey R: Therapeutic effects of glucagon on carbon monoxide poisoning. Annals Emergency Med 44: S92, 2004.

13. Cuadrado A and Rojo AI: Heme oxygenase- 1 as a therapeutic target in neurodegenerative diseases and brain infections. Curr Pharm Des 14: 429-442, 2008.

14. Zhu Y, Sun Y, Jin K and Greenberg DA: Hemin induces neuroglobin expression in neural cells. Blood 100: 2494-2498, 2002.

15. Guan L, Wen T, Zhang Y, Wang X and Zhao J: Induction of heme oxygenase-1 with hemin attenuates hippocampal injury in rats after acute carbon monoxide poisoning. Toxicology 262: 146-152, 2009.

16. Fechter LD, Thorne PR and Nuttall AL: Effects of carbon monoxide on cochlear electrophysiology and blood flow. Hear Res 27: 37-45, 1987.
17. Bruce RD: An up-and-down procedure for acute toxicity testing. Fundam Appl Toxicol 5: 151-157, 1985.

18. Hamilton MA, Russo RC and Thurston RV: Trimmed Spearman-Karber method for estimating median lethal concentrations in toxicity bioassays. Environmental Sci Technol 11: 714-719, 1977.

19. Ramieri A Jr, Jatlow P and Seligson D: New method for rapid determination of carboxyhemoglobin by use of double-wavelength spectrophotometry. Clin Chem 20: 278-281, 1974.

20. Placer ZA, Cushman LL and Johnson BC: Estimation of product of lipid peroxidation (malonyl dialdehyde) in biochemical systems. Anal Biochem 16: 359-364, 1966.

21. Todorova I, Simeonova G, Kyuchukova D, Dinev D and Gadjeva V: Reference values of oxidative stress parameters (MDA, SOD, CAT) in dogs and cats. Comparative Clinical Pathol 13: 190-194, 2005.

22. Nabeshima T, Katoh A, Ishimaru H, Yoneda Y, Ogita K, Murase K, Ohtsuka H, Inari K, Fukuta T and Kameyama T: Carbon monoxide-induced delayed amnesia, delayed neuronal death and change in acetylcholine concentration in mice. J Pharmacol Exp Ther 256: 378-384, 1991.

23. Sidman RL, Angevine JB and Pierce ET: Atlas of the mouse brain and spinal cord. Harvard University Press, Cambridge, Mass, 1971.

24. Raub JA, Mathieu-Nolf M, Hampson NB and Thom SR: Carbon monoxide poisoning-a public health perspective. Toxicology 145: $1-14,2000$.

25. Penney DG: Acute carbon monoxide poisoning: Animal models: A review. Toxicology 62: 123-160, 1990.

26. Lopez DM, Weingarten-Arams JS, Singer LP and Conway EE Jr: Relationship between arterial, mixed venous, and internal jugular carboxyhemoglobin concentrations at low, medium and high concentrations in a piglet model of carbon monoxide toxicity. Crit Care Med 28: 1998-2001, 2000.

27. Fechter LD, Thorne PR and Nuttall AL: Effects of carbon monoxide on cochlear electrophysiology and blood flow. Hear Res 27: 37-45, 1987.

28. Fan Y, Li J, Yin Q, Zhang Y, Xu H, Shi X, Li C, Zhou Y and Zhou C: Effect of extractions from Ephedra sinica Stapf on hyperlipidemia in mice. Exp Ther Med 9: 619-625, 2015.

29. Burmester T, Weich B, Reinhardt S and Hankeln T: A vertebrate globin expressed in the brain. Nature 407: 520-523, 2000.

30. Chen NC, Huang CW, Lui CC, Lee CC, Chang WN, Huang SH, Chen $\mathrm{C}$ and Chang CC: Diffusion-weighted imaging improves prediction in cognitive outcome and clinical phases in patients with carbon monoxide intoxication. Neuroradiology 55: 107-115, 2013.

31. Kurauchi Y, Hisatsune A, Isohama Y and Katsuki H: Nitric oxide-cyclic GMP signaling pathway limits inflammatory degeneration of midbrain dopaminergic neurons: Cell type-specific regulation of heme oxygenase-1 expression. Neuroscience 158: 856-866, 2009

32. Morse D and Choi AM: Heme oxygenase-1: From bench to bedside. Am J Respir Crit Care Med 172: 660-670, 2005.

33. Wu L and Wang R: Carbon monoxide: Endogenous production, physiological functions, and pharmacological applications. Pharmacol Rev 57: 585-630, 2005.

34. Elbirt KK and Bonkovsky HL: Heme oxygenase: Recent advances in understanding its regulation and role. Proc Assoc Am Physicians 111: 438-447, 1999.

35. Akyol S, Erdogan S, Idiz N, Celik S, Kaya M, Ucar F, Dane S and Akyol $\mathrm{O}$ : The role of reactive oxygen species and oxidative stress in carbon monoxide toxicity: An in-depth analysis. Redox Rep 19: 180-189, 2014.

36. Amemiya $S$, Kamiya $T$, Nito $C$, Inaba $T$, Kato $K$, Ueda $M$, Shimazaki K and Katayama Y: Anti-apoptotic and neuroprotective effects of edaravone following transient focal ischemia in rats. Eur J Pharmacol 516: 125-130, 2005.

37. Hampson NB, Simonson SG, Kramer CC and Piantadosi CA: Central nervous system oxygen toxicity during hyperbaric treatment of patients with carbon monoxide poisoning. Undersea Hyperb Med 23: 215-219, 1996.

38. Ulbrich F and Goebel U: Argon: A novel therapeutic option to treat neuronal ischemia and reperfusion injuries? Neural Regen Res 10: 1043-1044, 2015.

39. O'Donnell P, Buxton PJ, Pitkin A and Jarvis LJ: The magnetic resonance imaging appearances of the brain in acute carbon monoxide poisoning. Clin Radiol 55: 273-280, 2000. 